\title{
The Use of Urine as Free Fertilizer Increasing Plant Growth
}

\author{
David Beaune* \\ Société d'Ornithologie de Polynésie SOP Manu BP7023 98719Taravao, Tahiti, French Polynesia, \\ Biogéosciences, UMR 6282 CNRS, Université de Bourgogne Franche-Comté, 6 Boulevard Gabriel, 21000 \\ Dijon, France
}

*Corresponding Author: David Beaune,. Biogéosciences, UMR 6282 CNRS, Université de Bourgogne Franche-Comté, 6 Boulevard Gabriel, 21000 Dijon, France.david.beaune@ gmail.com

\begin{abstract}
Human urine is freely available around the world and is composed of nitrogen (N), inorganic potassium $(K)$, phosphorus $(P)$, and other nutrients directly absorbable by plants. This resource was tested on several tropical horticultural species and showed rapid positive effect on plants growing. In the nursery: 3 trees and 1 vine species were treated with $50 \mathrm{~mL}$ urine (1/3) + water (2/3) and compared to control $(50 \mathrm{~mL}$ of water). After 36 days of treatment, papaya tree, passion fruit vine, Serianthes myriadenia and Hibiscus tiliaceus treated with urine were significantly higher, greener and produced more leaves than control sister seedlings treated with water only. Human urine should be managed to keep valuable nutrients, benefiting for plants and food security and not treated as a waste product.
\end{abstract}

Keywords: Carica papaya, Hibiscus tiliaceus, horticulture, Passiflora edulis, organic, urine

\section{INTRODUCTION}

The green revolution in agriculture led many people to forget about basic ecological rules in agriculture and most of them did not think that animal wastes are recycled / reused by plants. That is why today, human urine is thrown in drinkable water followed by costly treatment as public sanitation, and chemical fertilizers are bought and used for agriculture. However human urine is composed of nitrogen (N) (as urea (75-90\%) and ammonium), inorganic potassium (K), phosphorus $(\mathrm{P})$, Calcium $(\mathrm{Ca})$, Sulphur $(\mathrm{S})$ and Magnesium $(\mathrm{Mg})^{3}$ directly absorbable by plants, similarly to commercial fertilizers (Pradhan et al., 2007, Egigu et al., 2014, Nagy and Zseni, 2017). It was shown to be as efficient as commercial fertilizers without pathogen risk, low $\mathrm{NH}_{3}$ emissions, no flavour effect, and has been tested positively on 6 different plant orders and families including tomatoes, cabbages, beans, corns, etc. (see table 1 with references). However, despite the importance of the subject, researches are recent, relatively rare and public still skeptical. Furthermore, I did not find scientific tests on horticultural species for food or wood production. This paper proposes to test human urine on tropical plant growth in horticultural nursery with tree and liana species. The target species are tropical plants used for fruit production (passion fruit, papaya) and tropical trees used for conservation purposes and reforestation programs (Beaune et al. 2018). The hypothesis is in accordance with general finding: trees and liana grow faster with human urine supplementation. The experimental design is simple in order to be easily reproducible by organic farmers and food security gardeners in developing tropical areas without chemist material.

\section{Material AND Methods}

The tree nursery is located in Taravao, Tahiti, French Polynesia (Latitude: -17.752531 | Longitude: 149.318388) with tropical climate. The nursery is not covered, but shadowed by surrounding trees and receives natural rain plus artificial watering during days without rain. To limit genetic variation, the papaya (N=50 VS 50) are from the same fruit, and passiflora (50 VS 50), Hibiscus (20 VS 20) and Serianthes (30 VS 30) seeds are from the same parental tree. Two lots (marked, control with water VS. urine supplementation) of each species are spatially mixed and randomly remixed every week in order to confound $\mu$-environmental factors (shadow, wind exposure, etc.). Seedlings planted at the same time in May 2017, are in black plastic pots $(5 \times 5 \times 10 \mathrm{~cm}$ high) filled with coconut coir; Weeds continuously removed. Plants were watered every three days with $50 \mathrm{~mL}$ of rain water (control) or 50 $\mathrm{mL}$ of urine treatment (1/3 of fresh human urine diluted in rain water). Human Urine compound varies 
among adults. The source is a healthy vegetarian male without medication (composition should be close to $\mathrm{N}=3.07 \pm 1.15 \mathrm{~g} / \mathrm{L}, \mathrm{K}=1.7 \pm 0.2, \mathrm{P}=0.02 \pm 0.004$ and $\mathrm{S}=1.17 \pm 0.12 \mathrm{~g} / \mathrm{L}$ found in (Ranasinghe et al., 2016). Watering was done at the base of the seedling to avoid leaf damage due to the ions (Jönsson et al., 2004, Vinnerås et al., 2003). Seedling height and leaf number was measured after 36 days of treatment and compared. Growths and leaf number were compared and difference tested using ad hoc parametric t-test or $\mathrm{W}$ according to normality with $\mathrm{R}$ statistical software (R Development Core Team, 2011).

Table1: Plant species showing positive results of growing with urine supplementation

\begin{tabular}{|l|l|l|l|l|}
\hline \multicolumn{1}{|c|}{ Order } & \multicolumn{1}{c|}{ Family } & Plant Name & \multicolumn{1}{c|}{ Species Name } & \multicolumn{1}{c|}{ Reference } \\
\hline Brassicales & Brassicaceae & cabbage & Brassica oleracea & (Pradhan et al., 2007) \\
\hline Brassicales & Caricaceae & papaya & Carica papaya & this study \\
\hline Caryophyllales & Amaranthaceae & beet & Beta vulgaris & (Egigu et al., 2014) \\
\hline Cucurbitales & Cucurbitaceae & cucumber & Cucumis sativus & (Heinonen-Tanski et al.,2007) \\
\hline Cucurbitales & Cucurbitaceae & pumpkin & Cucurbita maxima & (Pradhan et al., 2008) \\
\hline Fabales & Fabaceae & beans & Phaseolus vulgaris & (Ranasinghe et al., 2016) \\
\hline Fabales & Fabaceae & Faifai & Serianthes myriadenia & this study \\
\hline Malpighiales & Passifloraceae & passion fruit & Passiflora edulis & this study \\
\hline Malvales & Malvaceae & okra & Abelmoschus esculentus & (Akpan-Idiok et al. 2012) \\
\hline Malvales & Malvaceae & Hibiscus & Hibiscus tiliaceus & this study \\
\hline Poales & Poaceae & maize & Zea mays & (Guzha et al., 2005) \\
\hline Poales & Poaceae & Barley & Hordeum vulgare & (Heinonen-Tanski et al., 2007) \\
\hline Poales & Poaceae & wheat & Triticum sp & (Tidåker et al., 2007) \\
\hline Solanales & Solanaceae & tomatoe & Solanum lycopersicum & (Egigu et al., 2014, Mnkeni et al., \\
& & & & 2008, Pradhan et al., 2009) \\
\hline
\end{tabular}

\section{RESUltS}

Differences were clearly visible after only 36 days of treatment. For papaya, the seedlings that received urine were higher $(156 \pm S E .3 \mathrm{~cm}$ VS. $92 \pm 2$; p-value $<0.001)$, with more leaves $(13.4 \pm 4 \mathrm{VS}$ $6.8 \pm 2$; p-value $<0.001)$. Passion fruit vines receiving urine were longer $(119.1 \pm 3.5 \mathrm{~cm}$ VS $79.6 \pm 3.0)$ and with more leaves $(8.2 \pm 0.5$ VS $5.9 \pm 0.3$; p-value $<0.001)$. Hibiscus with urine were higher $(146.9 \pm 12.6 .1 \mathrm{~cm}$ VS $76.2 \pm 17.1$; p-value < 0.001$)$ and with more leaves $(8.6 \pm 0.7$ VS $5.0 \pm 1.1$; pvalue $<0.001)$. Serianthes with urine were higher $(241.2 \pm 6.3 \mathrm{~cm}$ VS. $185.2 \pm 12.5$; p-value $<0.001)$ with more leaves $(7.6 \pm 0.2$ VS $5.5 \pm 0.3$; p-value < 0.001). See figures 1 and 2 . All the plants for all the species presented greener leaves with urine treatment. See figure 3.
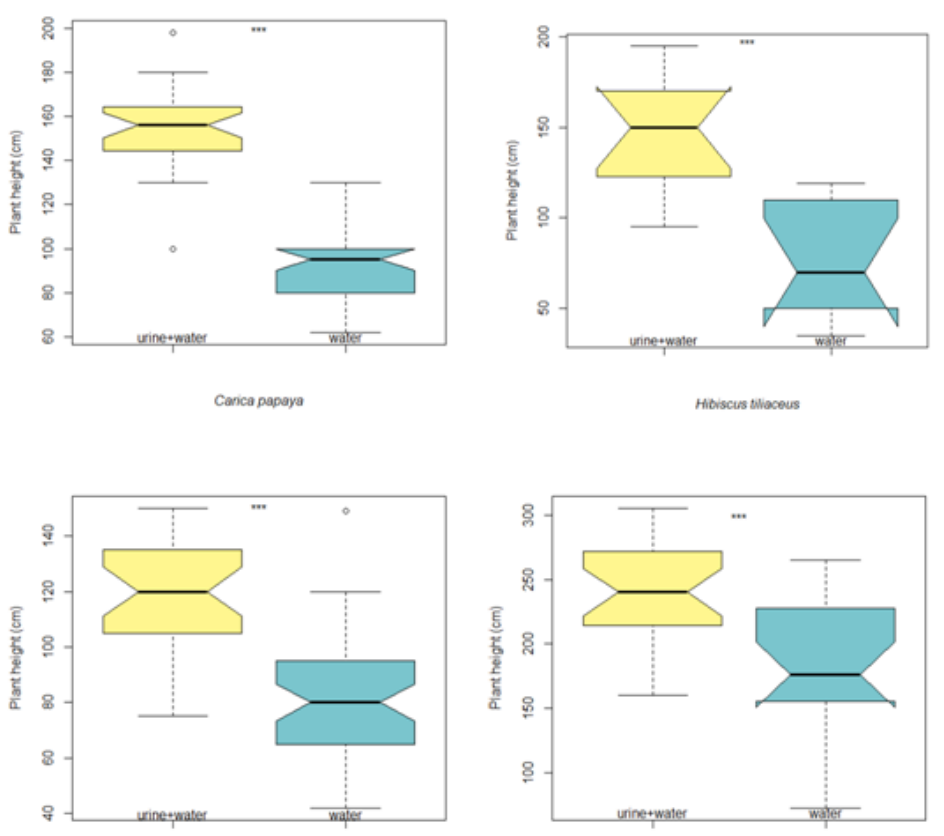

Passiflore odult

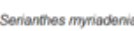

Figure1: Differences in height for 4 tropical horticultural plants treated with $50 \mathrm{~mL}$ of human urine (1/3 diluted within $+2 / 3$ of rain water) (yellow boxes) and control treated with $50 \mathrm{~mL}$ of rain water (blue boxes). *** indicate significant difference with p-value $<0.001$ ( $t$ or W tests) and Power analysis $>90 \%$. 


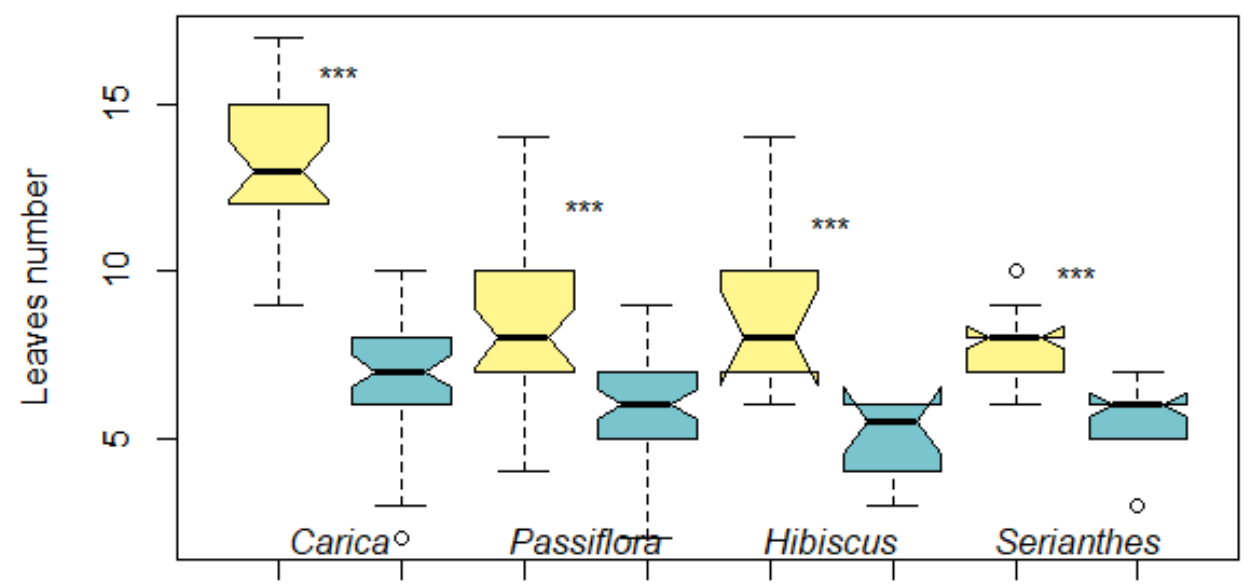

Plant species

Figure2 : Differences in leaves number produced for 4 tropical horticultural plants treated with $50 \mathrm{~mL}$ human urine (1/3 diluted within $+2 / 3$ of rain water) (yellow boxes) and control treated with $50 \mathrm{~mL}$ of rain water (blue boxes). *** indicate significant difference with p-value $<0.001$ ( $t$ or W tests) and Power analysis $>90 \%$.
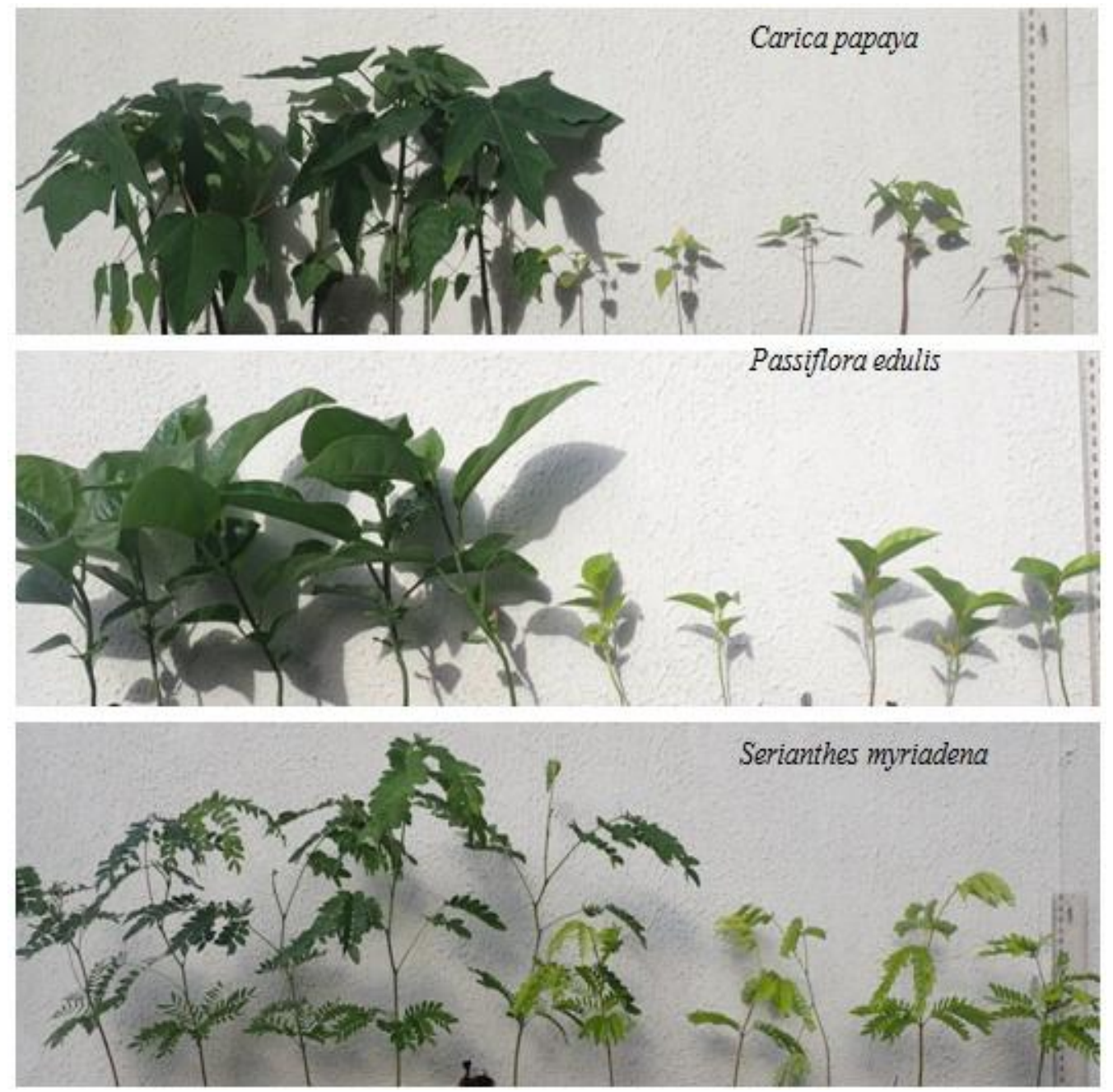

Figure3: Random samples of the tropical horticultural plants treated with $50 \mathrm{~mL}$ of human urine (1/3diluted within 2/3 of rain water) (4plants at the right) and control treated with $50 \mathrm{~mL}$ of rain water (4 left). 


\section{DISCUSSION}

As for crops and vegetables, trees and liana seem to benefit human urine supplementation $(50 \mathrm{~mL}$ of water with $1 / 3$ urine every 3 days). In this tropical area, the treated seedlings grow faster and develop more leaves. Furthermore and not measured here, the treated plants have greener and larger leaves than sister plants receiving only water, while popular thoughts is that urine can kill plants or make them yellow. This difference in leaves color is probably due to a lack of nutrients for yellow leaves. While urine is still considered as a valuable waste and a water management and sanitation problem in the majority of poor and rich countries, it should be considered as a nutrient resource. Each adult human produces 1-1.5L of free urine per day (this study) with $\mathrm{N}, \mathrm{P}$ and $\mathrm{K}$. In spite of being a problem, urine could become the new golden fertilizer and cities would be considered as new mines for resources (in spite of exploiting mines that degrade ecosystems). With new urban and sanitation organization, human urine could be collected and separated from feces and be used for agriculture and horticulture (Heinonen-Tanski and van Wijk-Sijbesma, 2005, Nagy and Zseni, 2017). Dosage and other treatments as ash and compost adds is also considered for efficiency, soil structure and improved nutrient content (Pradhan et al., 2009, Jönsson et al., 2004, Rodhe et al., 2004, Vinnerås et al., 2003). This is cost and environmental effective, for ecology, economy, organic farming and food security in developing countries or in our case, for horticulture of endemic trees for a conservation program.

\section{ACKNOWLEDGMENTS}

The SOP Manu plant nursery is funded for various conservation programs (see www.manu.pf) by the government (Direction de l'Environnement), the EU with BEST 2.0 \#1058, the Auckland zoo and the SOP Manu members. I thank Aurore Pernat and Gianluca Lazzari for assistance.

\section{REFERENCES}

[1] Akpan-Idiok, A. U., Udo, I. A. and Braide, E. I. (2012) 'The use of human urine as an organic fertilizer in the production of okra (Abelmoschus esculentus) in South Eastern Nigeria', Resources, Conservation and Recycling, 62, pp. 14-20.

[2] Beaune. D., Butaud J-F, and Boudjelas. s. (2018) 'Protocol fro Transferring Bare-rooted Native Plant Seedings to Restoration Sites-Preventing the Spread of Invasive Species Contaminatinants' International Journal of Research in Environmental Sciences. 4(1), pp 73-75.

[3] Egigu, M. C., Melak, B., Kebede, A. and Muthuswamy, M. (2014) 'Use of Human Urine as Fertilizer for Vegetable Cultivation', methods, 9, pp. 12.

[4] Guzha, E., Nhapi, I. and Rockstrom, J. (2005) 'An assessment of the effect of human faeces and urine on maize production and water productivity', Physics and Chemistry of the Earth, Parts A/B/C, 30(11), pp. 840-845.

[5] Heinonen-Tanski, H., Sjöblom, A., Fabritius, H. and Karinen, P. (2007) 'Pure human urine is a good fertiliser for cucumbers', Bioresource technology, 98(1), pp. 214-217.

[6] Heinonen-Tanski, H. and van Wijk-Sijbesma, C. (2005) 'Human excreta for plant production', Bioresource technology, 96(4), pp. 403-411.

[7] Jönsson, H., Stintzing, A. R., Vinnerås, B. and Salomon, E. (2004) Guidelines on the use of urine and faeces in crop production. EcoSanRes Programme.

[8] Mnkeni, P. N., Kutu, F. R., Muchaonyerwa, P. and Austin, L. M. (2008) 'Evaluation of human urine as a source of nutrients for selected vegetables and maize under tunnel house conditions in the Eastern Cape, South Africa', Waste management \& research, 26(2), pp. 132-139.

[9] Nagy, J. and Zseni, A. (2017) 'Human urine as an efficient fertilizer product in agriculture', Agronomy Research, 15(2), pp. 490-500.

[10] Pradhan, S. K., Pitkanen, S. and Heinonen-Tanski, H. (2008) 'Fertilizer value of urine in pumpkin (Cucurbita maxima L.) cultivation', Agricultural and Food Science, 19(1), pp. 57-68.

[11] Pradhan, S. K., Holopainen, J. K. and Heinonen-Tanski, H. (2009) 'Stored human urine supplemented with wood ash as fertilizer in tomato (Solanum lycopersicum) cultivation and its impacts on fruit yield and quality', Journal of agricultural and food chemistry, 57(16), pp. 7612-7617.

[12] Pradhan, S. K., Nerg, A.-M., Sjöblom, A., Holopainen, J. K. and Heinonen-Tanski, H. (2007) 'Use of human urine fertilizer in cultivation of cabbage (Brassica oleracea) -impacts on chemical, microbial, and flavor quality', Journal of agricultural and food chemistry, 55(21), pp. 8657-8663. 
[13] R core team (2011) R: A Language and Environment for Statistical Computing. Available at: http://www.R-project.org.

[14] Ranasinghe, E., Karunarathne, C., Beneragama, C. and Wijesooriya, B. (2016) 'Human urine as a low cost and effective nitrogen fertilizer for bean production', Procedia Food Science, 6, pp. 279-282.

[15] Rodhe, L., Richert Stintzing, A. and Steineck, S. (2004) 'Ammonia emissions after application of human urine to a clay soil for barley growth', Nutrient Cycling in Agroecosystems, 68(2), pp. 191-198.

[16] Tidåker, P., Mattsson, B. and Jönsson, H. (2007) 'Environmental impact of wheat production using human urine and mineral fertilisers-a scenario study', Journal of Cleaner Production, 15(1), pp. 52-62.

[17] Vinnerås, B., Jönsson, H., Salomon, E. and Stintzing, A. R. 'Tentative guidelines for agricultural use of urine and faeces'. Proceedings of the 2nd International Symposium on Ecological Sanitation, 101-107.

Citation: D. Beaune, "The Use of Urine as Free Fertilizer Increasing Plant Growth", International Journal of Forestry and Horticulture, vol. 4, no. 1, p. 24-28, 2018. http://dx.doi.org/10.20431/2454-9487.0401004

Copyright: (C) 2018 Authors. This is an open-access article distributed under the terms of the Creative Commons Attribution License, which permits unrestricted use, distribution, and reproduction in any medium, provided the original author and source are credited. 